This document is the accepted manuscript version of the following article:

Fischer, M. (2014). Coalition structures and policy change in a consensus democracy.

Policy Studies Journal, 42(3), 344-366. https://doi.org/10.1111/psj.12064

\title{
Coalition structures and policy change in a consensus democracy
}

\author{
MANUEL FISCHER Swiss Aquatic Science (Eawag) and University of Berne, Switzerland \\ manuel.fischer@eawag.ch
}

Article accepted for publication at the Policy Studies Journal (2014)

\begin{abstract}
This paper studies the relation between coalition structures in policy processes and policy change. While different factors such as policy images, learning processes, external events or venue shopping are important to explain policy change, coalition structures within policy processes are often neglected. However, policy change happens as a result of negotiations and coordination among coalitions within policy processes. The paper analyzes how conflict, collaboration, and power relations among coalitions of actors influence policy change in an institutional context of a consensus democracy. Empirically, I rely on a Qualitative Comparative Analysis to conduct a cross-sector comparison of the 11 most important policy processes in Switzerland between 2001 and 2006. Coalition structures with low conflict and strong collaboration among coalitions as well as structures with dominant coalitions and weak collaboration both facilitate major policy change. Competing coalitions that are separated by strong conflict, but still collaborate strongly produce policy outputs that are close to the status quo.
\end{abstract}

Keywords: Policy change, coalition structure, consensus democracy, policy process, Qualitative Comparative Analysis. 


\section{Introduction}

Policy change is needed in order for politics to adapt to a rapidly changing and increasingly complex world. Explaining policy change is a complex task, too. Scholars have been analyzing factors that favor or impede policy change, emphasizing policy images (Baumgartner 2012; Baumgartner and Jones 1993; Hall 1993), learning processes (Bennett and Howlett 1992; Sabatier 1987; Sabatier and Jenkins-Smith 1993), external events (Nohrstedt 2005; Sabatier and Jenkins-Smith 1993), strategies of venue shopping (Nohrstedt 2011; Pralle 2003) or actors' capacity to connect different policy subsystems (Hoberg and Morawski 2008; Jones and Jenkins-Smith 2009). Much less research is devoted to coalition structures within policy processes - specific actions within policy subsystems ${ }^{1}-$ that lead to major policy change or, on the contrary, status quo outputs.

This is surprising, as policy change results from changing legislation, and changing legislation is the output of a given policy process. Policy processes are governed by several competing coalitions (Sabatier 1987). Negotiations and coordination among these coalitions may or may not lead to policy change. Policy images, learning processes, venue shopping or external events are important to understand policy change. However, these factors are opportunity structures that influence the composition, resources and strategies of coalitions. If we want to understand the full dynamics of policy change, the coalition structure within a specific policy process is an important piece to solving the complex puzzle of explaining policy change.

Against this background, this paper asks what coalition structures in policy processes enable policy change. It suggests that certain coalition structures are more prone to policy change, while others favor a status quo output. Further, it takes into account opportunity structures for policy change at two levels: process-specific opportunity structures and country-specific opportunity structures. Process-specific opportunity structures relate to opportunity structures for policy change that are specific to the policy process and are given by the usual factors for 
explaining change, mentioned above. Country-specific opportunity structures refer to the broader institutional context wherein policy processes take place. The ability of policy processes to breed policy change crucially depends on the amount of consensus needed for policymaking (Gupta 2012; Sabatier and Weible 2007).

Empirically, I conduct a cross-sector comparison of the 11 most important policy processes in Switzerland between 2001 and 2006. ${ }^{2}$ Switzerland is an ideal-type of a consensus democracy (Lijphart 1999). Unlike studies focusing on a single policy process, this paper offers a fairly comprehensive view of the effects of coalition structures on policy outputs across a variety of policy processes, thereby enhancing confidence in the empirical findings. I rely on a combination of two methods, i.e. Social Network Analysis (SNA, Wasserman and Faust 1994) and Qualitative Comparative Analysis (QCA, Ragin 1987). SNA tools are used for the systematic identification of coalition structures across the 11 processes. QCA allows for a structured comparison of the 11 cases and the identification of configurations of coalition structures that lead to policy change. Data stem from approximately 250 face-to-face interviews with representatives of political actors as well as from written documents about the 11 processes.

The remainder of this paper is structured as follows. The next section discusses the theoretical link between coalition structures and policy change. The presentation of data and methods follows. Then, results are presented and discussed for each case. The last section presents some conclusions from this study.

\section{Coalition structures and policy change}

\section{Coalition structures, policy change and policy-process opportunity structures}

In an increasingly complex and rapidly changing world, policy change has always been a major scope of interest for scholars of public policy (Baumgartner 2012; Baumgartner and Jones 1993; Hall 1993; Howlett and Ramesh 1998; Sabatier and Jenkins-Smith 1993; Weible 
et al. 2011). Major policy change is given if a policy brings fundamental, paradigmatic changes to the respective policy subsystem. A policy output that mainly reiterates existing policies is conceived of as policy stability or status quo output (Hall 1993; Howlett and Cashore 2009). Between the two extremes, different orders of policy change have been described, such as incremental or minor policy change (Hall 1993).

The degree of policy change has been explained by different factors. For example, the changing institutional context as a consequence of changing venues of authority (Baumgartner 2012; Baumgartner and Jones 1993; Hall 1993), actors' ability to venue shop (Nohrstedt 2011; Pralle 2003) or to connect different policy subsystems (Hoberg and Morawski 2008; Jones and Jenkins-Smith 2009) have been shown to create opportunities for change. Also, external events can lead to changing policy images, a redistribution of resources or policy learning; each of which can again favor policy change (Nohrstedt 2005; Sabatier and JenkinsSmith 1993). I conceive of these factors as process-specific opportunity structures. They influence resources and strategies available to given actors and thereby affect the coalition structure and - ultimately - policy change (Sabatier 1987). However, the link between these factors and policy change is complex, and policy change still needs to be negotiated within a given policy process. In policy processes, coalition structures reflect the processes of bargaining and coordination among actors, and therefore affect the potential to produce given outputs.

Coalitions are groups of actors, i.e. political parties, state actors, interest groups with similar beliefs that engage in some degree of coordination in order to influence a policy process (Sabatier and Weible 2007). Forming coalitions allows actors to coordinate their actions, join organizational and financial resources, or demonstrate broad support for an issue (Mahoney 2007). Most often such coalitions form only around a given policy process (Knoke 2010) and are informal (Heaney 2006). Besides benefits, being part of a coalition also implies costs for actors, as they have to invest in internal coordination and communication efforts, and might 
have to compromise (Mahoney 2007; Schlager 1995). There are usually two or three coalitions present in a given policy process (Sabatier 1987). Policy change in policy processes is negotiated and coordinated among coalitions.

For example, Howlett and Ramesh (1998) discuss the influence of the number and types of actors and the degree of openness of and contestation within a subsystem on different types of policy change. Adam and Kriesi (2007) rely on conflict, collaboration and power between coalitions and suggest that given combinations of these coalition structures favor either policy change or status quo outputs. These claims have however only rarely been tested empirically (exceptions are Nohrstedt 2010; Sandström and Carlsson 2008). Following this work, I argue that given coalition structures are more prone to policy change, while others favor a status quo output. Arguably, coalition structures in itself cannot fully explain policy change (Smith 2000), but they are crucial elements between country-specific and process-specific opportunity structure and policy change.

\section{Coalition structures, policy change and country-specific opportunity structures}

Besides depending on process-specific opportunity structures, coalition structures and their ability to produce policy change crucially depend on country-specific opportunity structures, i.e. the institutional context within which policy processes take place. The institutional context has long been neglected in studies on coalitions in policy processes (Adam and Kriesi 2007; Weible et al. 2011). Institutions refer to the formal rules and informal norms that both constrain and enable the behavior of actors (North 1990; Ostrom 2005). Taking the countryspecific opportunity structures into account is absolutely crucial when studying coalition structures within policy processes and their ability to produce policy change (i.e. Howlett and Cashore 2009; Lijphart 1999; Radaelli et al. 2012). Most importantly, the degree of consensus necessary for policy change varies according to institutional requirements (Gupta 2012; Sabatier and Weible 2007). Consensual systems require a high degree of consensus for a 
given output to pass a policy process, not least because of the important veto points that allow minority coalitions to block policy processes (Lijphart 1999; Tsebelis 1995).

\section{Conflict, collaboration and power in coalition structures}

Conflict, collaboration and power relations among coalitions are three elements that indicate the degree to which actors in coalitions are able to achieve consensus. First, conflict among coalitions of actors is influenced by differences in belief systems. If coalitions fight over fundamentally different world views, values and problem definitions, core beliefs are at stake and conflict is expected to be more intense (Sabatier and Weible 2007). Given the lack of consensus, chances are high that the policy output corresponds to a lowest common denominator solution close to the status quo. If conflict among actors deals only with secondary aspects related to policy instruments, then the overall conflict is lower and actors can reach a solution more easily (see Sabatier 1987; Sabatier and Weible 2007). Low conflict facilitates the joint elaboration of major policy change (Provan and Kenis 2008).

A second indicator for the degree of consensus among coalitions is given by their collaboration. Collaboration is the basis for negotiations and can include the exchange of information, advice, or resources, learning, compromise seeking, or coordination within a coalition (Provan and Kenis 2008; Sabatier 1987; Sabatier and Weible 2007). Strong collaboration is said to lead to social capital norms of generalized reciprocity, encourage the emergence of trust, facilitate coordination and communication, reduce incentives for opportunism, and thus allow dilemmas of collective action to be resolved (e.g. Coleman 1990; Putnam 1995). Strong collaboration might induce actors to pass from a "bargaining" mode of interaction to a "problem-solving" mode of interaction (Scharpf 1988; 1997), where actors concentrate on long term goals such as the creation of value and better outcomes. Strong collaboration is therefore susceptible to foster policy change. 
Third, I take into account power relations among coalitions. Instead of a consensus among coalitions, there might be enough consensus within a dominant coalition. ${ }^{3}$ In such situations, the dominant coalition is able to enforce its preferred policy solution, and minority coalitions have a hard time in opposing change (Scharpf 1997: 45ff.). The existence of a dominant coalition does not lead to policy change if the dominant coalition is against change, yet if a dominant coalition favors change it can enable policy change. Conversely, in the presence of several competing coalitions, a solution can only be achieved either by a marginal majority decision, or by negotiations and compromise seeking. The existence of several competing coalitions impedes change because coalitions are able to mutually block each other and have to find a lowest common denominator solution.

\section{Expectations}

In the context of a consensual institutional system, I expect that either the presence of a dominant coalition or a combination of low conflict and strong collaboration can lead to policy change. In the first situation, minority coalitions are unable to impede policy change favored by the dominant coalition, independently of the collaboration and conflict patterns between them. In the second situation of low conflict and strong collaboration, coalitions might be able to produce policy change even if there exist several coalitions. Status quo outputs, on the contrary, are expected in situations of high conflict and low collaboration among competing coalitions.

Note that I explicitly refrain from making hypothetical claims about necessity and sufficiency, as the coalition structure is only one factor that influences policy outputs (Lubell et al. 2012). As discussed above, these factors interact with country-specific and process-specific opportunity structures. Further, as the empirical analysis is based on one type of political system and eleven cases only, I am unable to systematically test the joint influence of coalition structures and both types of opportunity structures on policy change. In the empirical 
comparison, I simply test the influence of coalition structures on policy change. The countryspecific opportunity structure is most important for understanding which type of coalition structure is able to produce change. It is taken into account by explicitly treating the consensual political system as a scope condition (e.g., Goertz 2006). The process-specific opportunity structures are more important in order to understand why given coalition structures formed. They are discussed when I go back to the cases after the comparative analysis.

\section{Case, data and methods}

\section{Institutional context in Switzerland}

Switzerland is known as the paradigmatic case of a consensus democracy (Kriesi and Trechsel 2008; Lijphart 1999). A political system like the Swiss one with a high number of veto-points grants opponents with several opportunities to block policy changes and thereby promote the status quo (Immergut 1990). Because of institutions such as the referendum or federalism (Kriesi and Trechsel 2008), policy change can only be successful if the policy process includes all important actors, and the policy favors or at least does not harm actors who have the power to activate veto-points during the policy process (Tsebelis 1995). This is why consensus democracies are famous for their broad integration and political stability, but also for their low innovation capacity (Lijphart 1999). Switzerland is no exception, as policy processes are generally slow and policy change is often only minor and incremental (Kriesi and Trechsel 2008; Linder 2009).

\section{Data on the 11 most important policy processes}

This paper compares the 11 most important policy processes in Switzerland between 2001 and 2006. The importance of the policy processes is based on a written expert survey among approximately 80 experts of Swiss politics conducted in 2007. Such a cross-sector comparison 
within one country has the advantage of keeping country-specific variables like the institutional design of the political system constant. The cases are: the $11^{\text {th }}$ pension reform; the program of budget relief 2003; the extension of the bilateral agreement on the free movement of persons and flanking measures; the bilateral agreement on the taxation of savings; the bilateral agreement on Schengen/Dublin; the law on nuclear energy; the law on the infrastructure fund; the new law on foreigners; the reform of fiscal equalization and tasks distribution; the new constitutional articles on education; and the law on telecommunication (see appendix for a short description of the cases). These 11 processes cover a wide range of different policy subsystems and can therefore inform us about Swiss politics in general. On the other hand, admittedly, these most important processes may not be representative for the whole population of policy processes in Switzerland. They mainly include cases of major policy change. Indeed, given that the Swiss political system is prone to the status quo, the fact that 8 out of 11 processes under study are considered to have led to more than only minor policy change indicates a selection bias. This selection bias is due to the importance of the processes. My analysis is thus able to identify conditions that lead to major policy change, but might be less suited to identify conditions leading to status quo outputs.

Data on the 11 processes were gathered through approximately 250 semi-structured interviews with individual representatives of collective actors involved in the policy processes. Based on positional, decisional, and reputational approaches ${ }^{4}, 20$ to 30 organizational actors per process were identified and interviewed. Interviews were conducted between February and July 2008 by the author of this paper and four specifically trained colleagues. In addition to the answers to the pre-structured questions, additional comments given by interview partners were noted in interview protocols and provide helpful information for the interpretation of the data and the in-depth knowledge of the cases. Additionally, official documents ${ }^{5}$ provided me with supplementary information on the 11 policy processes. 


\section{Qualitative Comparative Analysis}

The 11 cases are compared with a Qualitative Comparative Analysis (QCA, e.g. Ragin 1987; Rihoux and Ragin 2009; for an application in public policy, see Schlager and Heikkila 2009). QCA allows for the systematic comparison of usually a medium (5-50) number of cases and is based on set-theory and Boolean algebra. Cases are described by fuzzy-set values for both the causal conditions and the outcome to be explained. Fuzzy-set values lie between 0 and 1 and indicate to what degree a case is a member of a given set, for example the set of policy processes that lead to major policy change (Ragin 2008; Rihoux and Ragin 2009). Whereas a value of 1 indicates full membership of a case in the set of policy processes leading to major policy change, a value of 0.6 means that a process did not lead to major policy change, but that the output is still closer to major policy change than to the status quo (which is represented by a fuzzy-set value of 0 , i.e. full non-membership in the set of cases with major policy change). The fuzzy-value of 0.5 represents the crossover point, where there is maximum ambiguity as to whether a case is more in or more out of the respective set (Ragin 2000). A truth table is the basis of the analysis and presents all possible configurations of conditions. For each configuration of conditions (corresponding to a row in the truth table), the researcher then assesses the degree to which it is empirically related to the outcome. For each configuration, the assessment of this relation is based on all cases and is indicated by a consistency score ${ }^{6}$ Configurations that are consistently related to the outcome are included in the analysis. ${ }^{7}$ The method then reduces the configuration of conditions that are related to the outcome by eliminating redundant conditions and finally identifies necessary and sufficient conditions related to an outcome.

Describing complex cases with simple fuzzy-sets implies a simplification of the information, which is needed for a systematic comparison. The method however allows for complexity in the sense of causal complexity, i.e. the fact that several different combinations of causal conditions can lead to an outcome and that the effect of a condition is dependent on its 
combination with other conditions. Further, it is crucial to go back to the cases after the comparative analysis in order to check the applicability of the formal solution to each single case, and to possibly re-introduce some case complexity. In the present analysis, this is especially important because coalition structures should not only be related to policy change or status quo, but also to the process-specific opportunity structures discussed above.

\section{Calibration of outcome and conditions}

Measuring policy outputs is a difficult task because of the many elements a policy comprises (Howlett and Cashore 2009) and a general lack of agreement on how to evaluate them (Provan et al. 2009). Ideas of what constitutes policy change can largely diverge among political actors. Working with actors' perceptions is one possibility to overcome this problem (Klijn et al. 2010). We thus asked our interview partners to indicate their perception of change on a scale from 1 (close to status quo) to 5 (major policy change). The crossover point is defined at 3, which lies exactly between the theoretical minimum value of 1 and the theoretical maximum value of 5 and represents outputs corresponding to minor policy change. The average perception of actors about the outcome of each process was transformed into a fuzzy-value by simply rescaling the value on the $1-5$ scale to a $0-1$ scale. Table A1 in the appendix gives an overview of the calibration of the outcome. The output closest to a major policy change was achieved in the policy process leading to the new fiscal equalization scheme (fuzzy-value 0.76). This process is considered one of the most important reforms in the last decades in Switzerland, as it re-organizes the competences and financial flows among the Confederation and the cantons. On the contrary, the output of the policy process on the law on nuclear energy is the case with the fewest policy change, as it mainly extended existing regulation to the future (0.37). Note however that even this case is closer to minor policy change $(0.5)$ than to the status quo, which again confirms the case selection bias. Thus, 
while a status quo output corresponds to the ideal-typical extreme case, all cases under study lead to at least some policy change.

Before being able to assess conflict, collaboration, and power among coalitions of actors, actors need to be aggregated into coalitions. Social Network Analysis (Wasserman and Faust 1994) tools are applied to identify coalition structures in the 11 cases. Relying on such formal tools ensures that the same criteria are used for the identification of coalition structures across different types of actors and policy processes.

Actors in a coalition do not only have similar beliefs, but also need to coordinate their activities (Henry 2011; Schlager 1995; Weible and Sabatier 2005). Therefore, coalitions are identified with a two-step procedure. In a first step, actors are regrouped into blocks according to their profile of belief convergence and divergence. Based on a list comprising all actors participating in the process, interview partners were asked to select the actors with which their organization had mainly convergent or divergent beliefs concerning the issue at stake. This results in a directed matrix with positive values indicating convergence and negative values indicating divergence of beliefs. Blocks are then identified with the "balance"-procedure in Pajek (Batagelj and Mrvar 1996). This procedure continuously rearranges the matrix of actors until reaching an arrangement that is closest to a pre-defined structure with only positive within-block-ties and negative between-block-ties (Nooy et al. 2005). Deviations from this ideal arrangement are indicated with an error term that varies according to the number of blocks (Doreian and Mrvar 2009). I selected the block structure with the lowest error term. Depending on the case, this procedure results in 2 to 5 blocks. Because having the same beliefs is not enough for actors to form a coalition, the second step identifies actors within each block that collaborate at least indirectly (i.e. through another actor). Based on a list comprising all actors participating in the process, interview partners were asked to select the actors with which their organization was collaborating closely, i.e. had frequent contacts during the policy process. As collaboration always needs two actors, only reciprocated 
collaboration ties were used for the analysis. Based on this collaboration network among the actors within each block, I identified groups of actors that collaborate at least indirectly (by identifying 2-cliques in UCINET, Borgatti et al. 2002). ${ }^{8}$ This allows eliminating actors from blocks that have similar beliefs as the other actors, but are not well integrated in the collaboration structure within the block. ${ }^{9}$ An alternative criterion, i.e. direct collaboration, is too strict. For example, a coalition might be composed of some important, leading actors and some less important actors. These actors of lower importance do not need to collaborate directly as long as they all collaborate with the leading actors (Hojnacki 1998). Thus, actors sharing similar beliefs (step 1) and collaborating with each other at least indirectly (step 2) form a coalition. Similar beliefs are analyzed before collaboration because it is the more important criterion for the identification of a coalition. I rely on a broad and neutral definition of collaboration. Especially in a consensual system like the Swiss one, this implies that if actors collaborate, this does not necessarily mean that they agree on the substantive policy issue at stake. While internal collaboration is important for a coalition, collaboration also occurs across coalitions. The information on collaboration is therefore less adapted for the first step of the identification of coalitions.

Based on this, I assess conflict, collaboration, and power among coalitions. First, the assessment of conflict is based on the interview data described above. Conflict among coalitions is measured as the average of convergence/divergence relations among the coalitions identified before. This means that the convergence/divergence relations within a coalition are not taken into account, but only the convergence/divergence relations among actors belonging to different coalitions. Because it is very improbable that the theoretically possible minimum $(=0)$ and maximum $(=1)^{10}$ is achieved in reality, I rely on the minimum and maximum observed values for the definition of full (non)membership in the set. The crossover point is defined by the median observed value. The average convergence/divergence values are then rescaled into fuzzy-set values accordingly (see table 
A2 in the appendix). Second, the assessment of collaboration is again based on the interview data described above. Collaboration among coalitions is measured as the average of betweencoalitions' collaboration ties. This again means that only relations among actors belonging to different coalitions are taken into account. Whereas the maximum collaboration among coalitions could theoretically be 1 , such a strong collaboration is never achieved between opposing coalitions. Therefore, I rely on the observed maximum value to define the threshold for full (non)membership. The minimum is 0 , the crossover point is defined by the median observed value (see table A3 in the appendix). Third, coalition power is measured by reputational power. Based on a list comprising all actors participating in a given process, interview partners were asked to indicate those actors that, in their view, had been very influential. Based on these answers, I calculated the score of reputational power of each actor, which corresponds to the average of the judgments from all interview partners. The power of each coalition is calculated by aggregating the reputational power of each actor belonging to a coalition. ${ }^{11}$ The theoretical maximum power of a coalition is 1.00 (i.e. presence of only one coalition), the theoretical minimum is given by 0.33 (i.e. presence of three equally powerful coalitions). The crossover point is defined at 0.50 , i.e. if in the presence of three coalitions one coalition has $50 \%$ of power. The power score of the most powerful coalition per process is then transformed into a fuzzy-value according to the three qualitative anchors (i.e. maximum, minimum, crossover point; see table A4 in the appendix). Table 1 presents the fuzzy-values for the outcome (CHANGE), as well as for the three conditions (POWER, CONFL, COLLAB).

\section{---Table 1 about here---}

\section{Comparative analysis}

Sufficient conditions for major policy change $e^{12}$ 
The truth table for the analysis of sufficient conditions for major policy change appears in table 2. The combination of three conditions results in 8 possible configurations. The cases listed in the last column of each row are the strong members of the respective configuration, which are more inside than outside the relevant set. ${ }^{13}$ All analyses are conducted with the computer program fsQCA (Ragin et al. 2009).

\section{--- Table 2 about here ---}

In the truth table, the gap in the consistency scores between 0.93 and 0.89 is used as a threshold for coding the row as leading to "major policy change". This includes all cases leading to major policy change in the minimization procedure. The solution is presented in table 3. In Boolean algebra, “*” stands for “and”, “+” stands for “or”. Upper case letters indicate the presence of a condition, lower case letters represent its absence.

\section{--- Table 3 about here ---}

Two alternative types of coalition structures are able to produce major policy change. A first solution, in agreement with theoretical expectations, is given by low conflict and strong collaboration between coalitions. Independently of the power relations among coalitions, if coalitions are separated by only low conflict and collaborate intensely, they are able to achieve major policy change. Low conflict indicates only differences with respect to secondary aspects, which can be overcome by collaboration, i.e. negotiations and compromise finding among coalitions. A second solution is given by a coalition structure with a dominant coalition, strong conflict, and weak collaboration. The combination of strong conflict and weak collaboration is the exact opposite of the first solution. Under these circumstances, policy change can only be achieved in the presence of a dominant coalition. This result gives 
support to the expectation that if a dominant coalition favors change, it can indeed achieve major policy change. The fact that a situation with a dominant coalition and conflict among coalitions has to be combined with weak collaboration in order to produce change is interesting. Strong collaboration between coalitions is a sign that beliefs of the minority coalitions have partly influenced the policy output, which would negatively affect the degree of change.

Overall, results from the analysis of conditions for major policy change are consistent with the hypothesized relationships, but suggest that the story is more complicated than expected. Most importantly, and contrary to my expectations, a dominant coalition is not individually sufficient for policy change, but needs to be combined with low collaboration and strong conflict. However, conflict is probably not the main element in this explanation. The fact that I do not empirically observe a situation with a dominant coalition, low conflict, and weak collaboration does not allow the program to eliminate the factor of conflict from the solution, but theoretical reasons suggest that such a situation would also allow policy change.

\section{Sufficient conditions for status quo outputs}

Table 4 presents the truth table for status quo outputs. For the analysis, only the first configuration of conditions is considered as sufficient for a status quo output (the case represented by the configuration in the second row - the process on the law on telecommunication - is closer to major policy change than to the status quo). All the other rows are coded as $0 .^{14}$

\section{--- Table 4 about here ---}

Only one specific coalition structure with strong conflict, strong collaboration and competing coalitions leads to policy outputs close to the status quo. This solution is $89 \%$ consistent with 
the empirical observations, but covers only $55 \%$ of the outcome to be explained. Competing coalitions are able to mutually block each other, thus impeding policy change. This risk is even higher if conflict among coalitions is strong. The fact that strong collaboration is the third condition required for status quo policy outputs is surprising at first glance. However, strong collaboration together with strong conflict indicates a situation of negotiation (see Adam and Kriesi 2007), which is expected to result in a lowest common denominator result close to the status quo. Note that the solution for sufficient conditions for status quo outputs covers only two out of three cases with status quo outputs, i.e. the pension scheme reform and the law on nuclear energy. ${ }^{15}$ Yet, the finding supports the expectation that strong conflict and competing coalitions lead to status quo outputs. Strong collaboration, contrary to my expectations, also contributes to the fact that a coalition structure produces an output that comes close to the status quo.

\section{Discussion: back to the cases}

The following examples shall illustrate how the results of the QCA can help us to understand policy change or status quo outputs in single cases. Going back to the cases is important, as a QCA provides a structured comparison, but i) does not prove causality and ii) reduces case complexity to simple fuzzy-set values. 8 out of the 11 cases under study brought major policy change to the policy subsystem in question. Four of these cases are explained by the first combination of conditions, i.e. by the absence of conflict and strong collaboration among coalitions. In the cases of the education reform, the treaty on the taxation of savings and the infrastructure funds, the minority coalitions did not strongly oppose the solution defended by the dominant coalition. The policy output in all three cases was mainly a result of strong collaboration of experts and specialists, and representatives of the minority coalition were also included in the elaboration of the solution. With respect to process-related opportunity structures, a "hurting stalemate" and policy learning after an earlier failure of a process 
dealing with a similar issue was important in the case of the infrastructure funds. Venue shopping by policy entrepreneurs was key in the process leading to the education reform: Given the reluctance of the federal administration to deal with the issue, members of the respective parliamentary committee initiated a new process and carefully included the relevant actors. Finally, the connection between different processes was a key factor in withholding conflict in the process leading to the taxation of savings agreement. The minority coalition formed mainly between members of the Swiss People's Party strategically focused on two other processes (see below) in order to express their opposition against bilateral agreements between Switzerland and the EU.

In the case of the telecommunications reform, conflict among the three coalitions was clearly more intense than in the education reform and the taxation of savings agreement, but still quite low compared to other cases under study. The most important actors in this process were private firms, associations, and administrative agencies responsible for telecommunication, while political parties played a less important role due to the technical complexity of the issue. This is due to a process-specific opportunity structure: the process mainly happened in venues of the judicial and administrative system. In such a technical and administrative context, actors collaborated strongly and were able to elaborate a compromise solution. The output in this case was not considered a major, but still a minor policy change.

Four cases (law on foreigners, free movement of persons, new fiscal equalization scheme, Schengen/Dublin) are explained by the second path to major policy change, i.e. the combination of a dominant coalition, strong conflict and weak collaboration among coalitions. The new fiscal equalization scheme is the case that represents the strongest policy change. The reform tackled the very distribution of competences and financial flows between the central state and the federal units, i.e. the cantons. The main stakeholders, i.e. the agencies of the Federal Finance Administration and the cantons, were able to create a dominant coalition together with the center-right parties and the most important economic interest groups. Given 
that the organization of the federal system was at stake, such a dominant coalition including representatives from both levels of the federal state was absolutely crucial for the reform to be successful. A minor opposition coalition was composed of the left parties and trade unions. These actors were against the reform because they feared potential negative consequences of competence redistribution from the Confederation to the cantons in the domain of social policy and health care. While a few amendments were introduced into the reform in order to counter the criticisms, collaboration with the minority coalition was rather weak, and the innovative character of the reform was not put into question by these minor amendments. By not collaborating strongly with the challengers, the dominant coalition took the risk of a defeat in a popular vote. However a majority of the population voted for the reform, allowing the dominant coalition to introduce major policy change.

The story for the free movement of persons and the treaty on Schengen/Dublin is similar. In these cases, state actors responsible for international negotiations with the European Union (EU) made specific efforts to build up a dominant coalition (including with the Left for the case of the free movement of persons, see Fischer and Sciarini 2013). There was weak collaboration with the minority coalition composed of members from the conservative Right. The dominant coalition made only limited concessions, such as transition periods in the case of the free movement of persons. It then took the risk of a popular vote, and was compensated for it by being able to introduce major policy change. The process-specific opportunity structure for policy change in these two cases of bilateral agreements with the EU is given by external events: Switzerland had to adapt to the EU policy to avoid lagging behind on important issues. In the case of the law on foreigners, a dominant coalition was formed very early in the process. A center-right coalition supported a more restrictive policy towards foreigners. Collaboration with the minority coalition of the Left was weak, which means that only minor concessions were made. The lack of compromise was responsible for policy 
change, but also resulted in the Left calling for a referendum. Given the dominant coalition favoring policy change, the referendum was however not successful.

Three of the 11 policy outputs are considered as being closer to the status quo than to major policy change (pension scheme reform, law on nuclear energy, program of budget relief). The QCA allowed the identification of sufficient combination of conditions for two of the cases, i.e. the pension scheme reform and the law on nuclear energy. In both cases, three competing coalitions were opposed by conflictive relations, and still collaborated among each other. In such situations of negotiation between competing coalitions, major policy change is difficult to achieve. The result of the policy process on the pension scheme reform is telling in this respect: while the right won the final vote in parliament, the left won the popular vote, and no result at all came out of the policy process. ${ }^{16}$

\section{Conclusions}

The goal of this paper is to contribute to the understanding of policy change. It focuses on the concrete policy process where policy change is negotiated between coalitions. Whereas the analytical focus lies on the relation between coalition structures and policy change, the paper also explicitly takes into account process-specific and country-specific opportunity structures. The bulk of the literature explaining policy change focuses on process-specific opportunity structures such as learning, external events, changing policy images, or opportunities for venue shopping. While these are important conditions that enable policy change and can help us understand why a given coalition structure forms, concrete change still needs to be negotiated among coalitions of actors within a given policy process. Country-specific opportunity structures are often not explicitly accounted for in empirical studies. Consensual systems as studied in this paper require a high degree of consensus for a given output to pass a policy process (Lijphart 1999; Tsebelis 1995). 
The analysis focuses on three important aspects of coalition structures that inform about the degree of consensus among coalitions, i.e. conflict, collaboration, and power relations. Irrespective of coalition size, weak conflict with strong collaboration among coalitions facilitates major policy change. In situations of strong conflict, policy change is still possible if a dominant coalition defends a solution of major policy change and does not collaborate with minority coalitions. While strong collaboration among coalitions facilitates major policy change in the absence of conflict (and independently of coalition size), it favors a policy output close to the status quo when competing coalitions are separated by strong conflict. The absence of collaboration can even be beneficial for policy change: a dominant coalition defending policy change and collaborating only weakly with minority coalitions is less susceptible to making concessions with minority coalitions and thereby to reduce the innovative character of the policy. Further, the existence of a dominant coalition favors major policy change - if collaboration with minority coalitions is weak. Note that a dominant coalition does of course not lead to policy change if policy change is not what the dominant coalition is aiming at. The case of the program of budget relief is a case at hand: even if the coalition structure would have enabled policy change, no major policy change came out of this process, as this was not the goal of actors. A situation with competing coalitions, on the contrary, rather leads to status quo outputs - especially if conflict is strong and collaboration weak. True, these results are not particularly surprising, but they systematically demonstrate a relation between coalition structures in policy processes and policy change.

Contrary to single case studies, the comparison of 11 different policy processes and outputs offers a fairly broad view on the question under study. While this extraordinary comparison certainly increases confidence in the findings, one should be careful with generalizing the results from this analysis. The most important policy processes mostly inform us about the outputs that are supposed to have the most important consequences on the functioning of the state and society - i.e. processes leading to major policy change. Thus, analyzing the most 
important coalition structures allowed me to explain situations of major policy change. On the contrary, given the bias in case selection, I refrain from making strong conclusions about conditions leading to status quo outputs.

Further, when considering the results, it is important to keep in mind that they are based on the scope condition of a consensual democracy. There is nothing I can conclude about other institutional contexts. It is for example possible that in more majoritarian types of political systems, coalition structures with competing coalitions and strong conflict enable policy change. An additional caveat is given by the fact that major policy change is rare in Switzerland due to the strong veto points existing in its consensual political system. The major policy changes might thus correspond to only minor policy changes when compared to other political systems. Further studies might want to analyze what coalition structures lead to major policy change in less important policy processes or in a different institutional setting, such as a majoritarian democracy. However, the coalition structure within policy processes, together with country- and process-specific opportunity structures, needs to be taken into account in order to properly understand policy change.

Manuel Fischer is a researcher at Eawag (Swiss Federal Institute for Aquatic Research and Technology) and a lecturer at the Institute of Political Science at the University of Berne, Switzerland. He is currently working on the characteristics and transformations of political decision-making and political networks, with a focus on environmental and water governance. His work has been published in the Journal of Public Policy, the Journal of European Public Policy, Global Environmental Change, Regional and Federal Studies and the Policy Studies Journal, among others. 


\section{Notes}

The author would like to thank Sandrine Bossy, David Keller, Guenda Malinverni, and Denise Traber who contributed to the data gathering. This article is part of a wider research project sponsored by the Swiss Science Foundation (Grant No. 100012-113964). Thanks for their helpful comments also go to Karin Ingold, Pascal Sciarini, and to the editor and three anonymous reviewers of this journal.

${ }^{1}$ While "policy subsystem" describes a set of interrelated issues in a functional/substantive or territorial dimension and a set of actors interested in these issues (Sabatier and Weible 2007), "policy process" refers to a particular process taking place within a policy subsystem.

${ }^{2}$ The importance of the policy processes is based on a written expert survey among approximately 80 experts of Swiss politics conducted in 2007.

${ }^{3}$ The existence of a dominant coalition points towards a policy monopoly in the policy subsystem, which would rather impede policy change (Baumgartner and Jones 1993; True et al. 2007). However, the focus of this paper is not on entire policy subsystems, but on single policy processes (see FN 1). It studies which coalition structures within a single policy process enable policy change. A dominant coalition might not have existed before, but forms only within a single policy process as a consequence of process-related opportunity structures.

${ }^{4}$ First, following the decisional approach, I identified actors that took part in the different venues (e.g. expert committees, consultation procedure, parliamentary committees, etc.) of the 11 policy processes. To this list, I added the actors holding an overall strategic position in the Swiss political system (positional approach). Finally, I checked during the first interviews conducted with the administrative actors responsible for the policy process that no powerful actor was missing (reputational approach) (e.g. Knoke 1993: 30).

${ }^{5}$ I relied on mainly two types of official documents to get in-depth case knowledge: the report on the consultation procedure (i.e. a summary of actors positions with respect to the first project draft) and the report that government hands over to parliament together with the legislative project.

${ }^{6}$ The consistency score provides information on the extent to which the empirical observation supports the postulate of a perfect relationship between the conditions and the outcome, or how well the solution formula describes the cases. The coverage score (see table 3) is an indicator of the empirical importance of a relationship. It indicates what proportion of the fuzzy-membership values of the cases in the set of the outcome can be explained by the solution (Ragin 2008). 
${ }^{7}$ The choice of thresholds for including configurations can be guided by major gaps in the observed consistency
scores or by the inclusion of all strong members of the outcome set. The threshold should not be lower than 0.75 (Ragin 2008).

${ }^{8}$ Indirect collaboration refers to collaboration through a third actor. In network analysis, a 2-clique is defined as a set of nodes (actors) within which each node is connected to each other node at least indirectly, i.e. members of the 2-clique can reach each other through at most one intermediary. Alternatively, a 1-clique is defined as a set of nodes within which each node is connected to each other node directly (Wassermann and Faust 1994).

${ }^{9}$ Within each block identified before, the 2-cliques with the highest internal collaboration density was selected. Within a set of nodes that are connected by a set of ties, several different subsets of nodes can satisfy the minimum criteria of being at least indirectly connected. Selecting the subset of nodes with the highest internal collaboration density makes sure that from all sets of nodes that satisfy the minimum criteria, the one wherein actors collaborate most strongly is defined as the coalition.

${ }^{10}$ I rescaled the convergence/divergence variable from $-1 / 1$ to $0 / 1$ for this step of the analysis.

${ }^{11}$ The aggregation is computed as follows: First, I calculated the average reputational power of each actor in the coalition. Second, I calculated the sum of reputational power scores of all actors in the coalitions. Both scores were then standardized (so that the total power of all coalitions together is $100 \%$ ). Finally, I calculated the mean between the both scores to end up with a power score for each coalition.

${ }^{12}$ The analysis of necessity reveals that none of the conditions is necessary for either of the outcomes, relying on a consistency threshold of $90 \%$ (Schneider and Wagemann 2012). The respective table can be found in the appendix (table A5).

${ }^{13}$ Rows representing combinations of conditions without strong members in the empirical data are not directly relevant and do not appear in the truth table. The 11 cases have strong members in 5 of the 8 possible combinations of conditions; there are thus three possible configuration not observed in reality. The solutions are only based on the empirical observations and make no assumptions about the potential outcome for the nonobserved configurations (Ragin 2008: 160ff.).

${ }^{14}$ The solution is robust with respect to the choice of a different, i.e. lower threshold. Choosing a lower threshold of 0.75 includes all three cases that are closer to the status quo than to major policy change. The solution (power*COLLAB + CONFL*COLLAB) is substantially very similar to the solution of the original analysis (power*COLLAB*CONFL), i.e. strong conflict, strong collaboration, and competing coalitions are elements of coalition structures that lead to status quo outputs. 
${ }^{15}$ An alternative calibration of the outcome does not lead to a better explanation for status quo outcomes. If the crossover point is defined at an average value of 3.5 , six of the 11 cases belong more to the set of status quo outputs than the set of policy change outputs. This calibration produces two configurations that lead to status quo outputs (power*COLLAB + CONFL*COLLAB) which is very similar to the original solution, i.e. strong conflict, strong collaboration, and competing coalitions are elements of coalition structures that lead to status quo outputs.

${ }^{16}$ The third case of a status quo output is the program on budget relief. Despite a coalition structure with a dominant coalition, strong conflict and strong collaboration, no major policy change resulted from this process. This can be probably be explained that a program including only budget cuts can hardly represent major policy change. 


\section{References}

Adam, Silke, and Hanspeter Kriesi. 2007. "The Network Approach." In Paul A. Sabatier, ed. Theories Of The Policy Process. Boulder, Colorado: Westview Press, 129-54

Batagelj, Vladimir, and Andrej Mrvar. 1996. PAJEK - Program for Large Network Analysis.

Baumgartner, Frank R., and Bryan D. Jones. 1993. Agendas and Instability in American Politics. Chicago: The University of Chicago Press.

Baumgartner, Frank R. 2012. "Ideas and Policy Change." Governance 26 (2): 239-58.

Bennett, Colin J., and Michael Howlett. 1992. "The lessons of learning: Reconciling theories of policy learning and policy change." Policy Sciences 25 (3): 275-94.

Borgatti, S.P., M.G. Everett, and L.C. Freeman. 2002. Ucinet for Windows: Software for Social Network Analysis. Harvard, MA: Analytic Technologies.

Coleman, James S. 1990. Foundations of Social Theory. Cambridge, MA: Harward University Press.

Doreian, Patrick, and Andrej Mrvar. 2009. "Partitioning signed social networks." Social Networks 31: 1-11.

Fischer, Manuel, and Pascal Sciarini. 2013. "Europeanization and the inclusive strategies of executive actors." Journal of European Public Policy 20 (10): 1482-98.

Goertz, Gary. 2006. Social Science Concepts - A User's Guide. Princeton / Woodstock: Princeton University Press.

Gupta, Kuhika. 2012. "Comparative Public Policy: Using the Comparative Method to Advance Our Understanding of the Policy Process." Policy Studies Journal 40 (1): 1126.

Hall, Peter A. 1993. "Policy Paradigms, Social Learning, and the State: The Case of Economic Policymaking in Britain." Comparative Politics 25 (3): 275-96.

Heaney, Michael. 2006. "Brokering Health Policy: Coalitions, Parties, and Interest Group Influence." Journal of Health Politics, Policy and Law 31 (5): 887-944. 
Henry, Adam Douglas. 2011. "Ideology, Power, and the Structure of Policy Networks." Policy Studies Journal 39 (3): 361-83.

Hoberg, George, and Edward Morawski. 2008. "Policy change through sector intersection: forest and aboriginal policy in Clayoquot Sound." Canadian Public Administration 40 (3): $387-414$

Hojnacki, Marie. 1998. "Organized Interests' Advocacy Behavior in Alliances." Political Research Quarterly 51 (2): 437-59.

Howlett, Michael, and M. Ramesh. 1998. "Policy Subsystem Configurations and Policy Change: Operationalizing the Postpositivist Analysis of the Politics of the Policy Process." Policy Studies Journal 26 (3): 466-81.

Howlett, Michael, and Benjamin Cashore. 2009. "The Dependent Variable Problem in the Study of Policy Change: Understanding Policy Change as a Methodological Problem." Journal of Comparative Policy Analysis: Research and Practice 11 (1): 33-46.

Immergut, Ellen M. 1990. "Institutions, Veto Points and Policy Results: A Comparative Analysis of Health Care." Journal of Public Policy 10 (4): 391-416.

Jones, Michael D., and Hank C. Jenkins-Smith. 2009. "Trans-Subsystem Dynamics: Policy Topography, Mass Opinion, and Policy Change." The Policy Studies Journal 37 (1): $37-58$.

Klijn, Erik-Hans, Barm Steijn, and Jurian Edelenbos. 2010. "The Impact of Network Management on Outcomes in Governance Networks." Public Administration 88 (4): 1063-82.

Knoke, David. 2010. "Policy Networks." In Peter Carrington and John Scott, eds. The SAGE Handbook of Social Network Analysis. SAGE Publications, 210-22

Kriesi, Hanspeter, and Alexander H. Trechsel. 2008. The Politics of Switzerland. Cambridge: Cambridge University Press. 
Lijphart, Arend. 1999. Patterns of democracy: Government forms and performance in thirtysix countries. New Haven: Yale University Press.

Linder, Wolf. 2009. "Schweizerische Konkordanz im Wandel." Zeitschrift für Staats- und Europawissenschaften 7 (2): 207-30.

Lubell, Mark, John Scholz, Ramiro Berardo, and Garry Robins. 2012. "Testing Policy Theory with Statistical Models of Networks." The Policy Studies Journal 40 (3): 351-74.

Mahoney, Christine. 2007. "Networking vs. allying: the decision of interest groups to join coalitions in the US and the EU." Journal of European Public Policy 14 (3): 366-83.

Nohrstedt, Daniel. 2005. "External shocks and policy change: Three Miles Island and Swedish nuclear energy policy." Journal of European Public Policy 12 (6): 1041-59.

—. 2010. "Do Advocacy Coalitions Matter? Crisis and Change in Swedish Nuclear Energy Policy." Journal of Public Administration Research and Theory 20: 309-33. . 2011. "Shifting Resources and Venues Producing Policy Change in Contested Subsystems: A Case Study of Swedish Signals Intelligence Policy." Policy Studies Journal 39 (3): 461-84.

Nooy, Wouter De, Andrej Mrvar, and Vladimir Batagelj. 2005. Exploratory Social Network Analysis with Pajek. New York: Cambridge University Press.

North, Douglas C. 1990. Institutions, institutional change and economic performance. Cambridge: Cambridge University Press.

Ostrom, Elinor. 2005. Understanding institutional diversity. Princeton: Princeton University Press.

Pralle, Sarah B. 2003. "Venue Shopping, Political Strategy, and Policy Change: The Internationalization of Canadian Forest Advocacy." Journal of Public Policy 23 (3): 233-60. 
Provan, Keith G., and Patrick Kenis. 2008. "Modes of Network Governance: Structure, Management, and Effectiveness." Journal of Public Administration Research and Theory 18: 229-52.

Provan, Keith G., Kun Huang, and H. Brinton Milward. 2009. "The Evolution of Structural Embeddedness and Organizational Social Outcomes in a Centrally Governed Health and Human Services Network." Journal of Public Administration Research and Theory 19: 873-93.

Putnam, Robert D. 1995. "Bowling Alone: America's Declining Social Capital." Journal of Democracy 6 (1): 65-78.

Radaelli, Claudio M., Bruno Dente, and Samuele Dossi. 2012. "Recasting institutionalism: institutional analysis and public policy." European Political Science 11: 537-50.

Ragin, Charles, Kriss A. Drass, and Sean Davey. 2009. "Fuzzy-Set/Qualitative Comparative Analysis 2.5."

Ragin, Charles C. 1987. The Comparative Method. Moving Beyond Qualitative and Quantitative Strategies. Berkeley: University of California Press.

-2000. Fuzzy-set social science. Chicago: The University of Chicago press.

- 2008. Redesigning Social Inquiry: Fuzzy-Sets and Beyond. Chicago/London: University of Chicago Press.

Rihoux, Benoît, and Charles C. Ragin. 2009. Configurational Comparative Methods: Qualitative Comparative Analysis (QCA) and Related Techniques. Thousand Oaks/London: SAGE Publications.

Sabatier, Paul A. 1987. "Knowledge, Policy-Oriented Learning, and Policy Change: An Advocacy Coalition Framework." Science Communication 8: 649-92.

Sabatier, Paul A., and Hank Jenkins-Smith, eds. 1993. Policy Change and Learning: An Advocacy Coalition Approach. Boulder: Westview Press. 
Sabatier, Paul A., and Christopher M. Weible. 2007. "The Advocacy Coalition Framework." In Paul A. Sabatier, ed. Theories of the Policy Process. Boulder, Colorado: Westview Press, $189-222$

Sandström, Annica, and Lars Carlsson. 2008. "The Performance of Policy Networks: The Relation between Network Structure and Network Performance." Policy Studies Journal 36 (4): 497-524.

Scharpf, Fritz W. 1988. "The Joint-Decision Trap: Lessons from German Federalism and European Integration." Public Administration 66: 239-78.

1997. Games Real Actors Play: Actor-Centered Institutionalism in Policy Research. Boulder, Colorado / Oxford: Westview Press.

Schlager, Edella, and Tanya Heikkila. 2009. "Resolving Water Conflicts: A Comparative Analysis of Interstate River Compacts." The Policy Studies Journal 37 (3): 367-92.

Schlager, Edella C. 1995. "Policy Making and Collective Action: Defining Coalitions Within the Advocacy Coalition Framework." Policy Sciences 28: 243-70.

Schneider, Carsten Q., and Claudius Wagemann. 2012. Set-Theoretic Methods for the Social Sciences: A guide to Qualitative Comparative Analysis. Cambridge / New York: Cambridge University Press.

Smith, Adrian. 2000. "Policy networks and advocacy coalitions: explaining policy change and stability in UK industrial pollution policy?" Environment and Planning C: Government and Policy 18: 95-114.

True, James L., Bryan D. Jones, and Frank R. Baumgartner. 2007. "Punctuated-Equilibrium Theory: Explaining Stability and Change in Public Policymaking." In Paul A. Sabatier, ed. Theories of the policy process. Boulder, Colorado: Westview Press, 15588 
Tsebelis, George. 1995. "Decision Making in Political Systems: Veto Players in Presidentialism, Parliamentarism and Multipartyism." British Journal of Political Science 25 (3): 289-325.

Wasserman, Stanley, and Katherine Faust. 1994. Social Network Analysis. Methods and Applications. Cambridge University Press.

Weible, Christopher M., and Paul A. Sabatier. 2005. "Comparing Policy Networks: Marine Protected Areas in California." The Policy Studies Journal 33 (2): 181-201.

Weible, Christopher M., Paul A. Sabatier, Hank C. Jenkins-Smith, Daniel Nohrstedt, Adam Douglas Henry, and Peter Deleon. 2011. "A Quarter Century of the Advocacy Coalition Framework: Introduction to the Special Issue." The Policy Studies Journal 39: $349-360$. 
Tables

Table 1: Fuzzy-values of outcome and conditions CHANGE POWER CONFLICT COLLAB

\begin{tabular}{lllll}
\hline Nuclear & 0.37 & 0.32 & 0.68 & 0.50 \\
Pension & 0.46 & 0.09 & 0.71 & 0.77 \\
Fiscal equal. & 0.76 & 0.64 & 0.65 & 0.46 \\
Budget & 0.41 & 0.75 & 0.81 & 0.73 \\
Persons & 0.57 & 0.77 & 0.58 & 0.00 \\
Savings & 0.64 & 0.79 & 0.00 & 0.62 \\
Schengen & 0.70 & 0.67 & 1.00 & 0.46 \\
Foreigners & 0.52 & 0.74 & 0.87 & 0.12 \\
Education & 0.63 & 0.89 & 0.25 & 0.85 \\
Telecom & 0.52 & 0.41 & 0.41 & 1.00 \\
Infrastructure & 0.70 & 0.58 & 0.03 & 0.50 \\
\hline
\end{tabular}


Table 2: Truth table for the analysis of policy change

\begin{tabular}{|c|c|c|c|c|c|}
\hline POWER & CONFL & COLLAB & Consistency & CHANGE & Strong members \\
\hline 0 & 0 & 1 & 0.97 & 1 & Telecom \\
\hline 1 & 0 & 1 & 0.97 & 1 & $\begin{array}{l}\text { Education, Savings, } \\
\text { Infrastructure }\end{array}$ \\
\hline 1 & 1 & 0 & 0.93 & 1 & $\begin{array}{l}\text { Foreigners, Persons, Fiscal } \\
\text { equal., Schengen }\end{array}$ \\
\hline 1 & 1 & 1 & 0.89 & 0 & Budget \\
\hline 0 & 1 & 1 & 0.86 & 0 & Pension, Nuclear \\
\hline
\end{tabular}


Table 3: Complex solution for the outcome "policy change“

\begin{tabular}{lcccc}
\hline & Consistency & $\begin{array}{c}\text { Raw } \\
\text { coverage }\end{array}$ & $\begin{array}{c}\text { Unique } \\
\text { coverage }\end{array}$ & Cases covered \\
\hline confl*COLLAB & 0.95 & 0.58 & 0.37 & $\begin{array}{c}\text { Savings, Telecom, } \\
\text { Education, } \\
\text { Infrastructure }\end{array}$ \\
POWER*CONFL*collab & 0.93 & 0.48 & 0.27 & $\begin{array}{c}\text { Fiscal, Schengen, } \\
\text { Persons, Foreigners }\end{array}$ \\
\hline $\begin{array}{l}\text { Solution: } \\
\text { Total consistency } \\
\text { Total coverage }\end{array}$ & $\begin{array}{c}\text { confl*COLLAB + POWER*CONFL*collab } \\
\end{array}$ & 0.93 & & \\
\hline
\end{tabular}


Table 4: Truth table for the analysis of status quo

\begin{tabular}{cccccl} 
POWER & CONFL & COLLAB & Consistency & change & Strong members \\
\hline 0 & 1 & 1 & 0.89 & 1 & Pension, Nuclear \\
0 & 0 & 1 & 0.87 & 0 & Telecom \\
1 & 1 & 1 & 0.81 & 0 & Budget \\
1 & 1 & 0 & 0.72 & 0 & $\begin{array}{l}\text { Foreigners, Fiscal equal., } \\
\text { Persons, Schengen }\end{array}$ \\
1 & 0 & 1 & 0.71 & 0 & $\begin{array}{l}\text { Education, Savings, } \\
\text { Infrastructure }\end{array}$ \\
\hline
\end{tabular}




\section{Appendix}

Table A1: Calibration of the outcome

\begin{tabular}{llc}
\hline Policy change & $\begin{array}{l}\text { Cases (average policy } \\
\text { change in brackets) }\end{array}$ & Fuzzy-value \\
\hline Major policy change, theoretical maximum value & $\begin{array}{c}\text { (5.00): } \\
\text { Fiscal equal. (4.05) }\end{array}$ & 1.00 \\
& Infrastructure (3.79) & 0.76 \\
& Schengen (3.78) & 0.70 \\
& Savings (3.54) & 0.70 \\
& Education (3.52) & 0.64 \\
& Persons (3.26) & 0.63 \\
& Foreigners (3.09) & 0.58 \\
Crossover point: theoretical median value (3.00): & Telecom (3.07) & 0.52 \\
& Pension (2.84) & 0.50 \\
& Budget (2.64) & 0.46 \\
Status quo, theoretical minimum value (1.00): & Nuclear (2.47) & 0.41 \\
& & 0.37 \\
\hline
\end{tabular}


Table A2: Calibration of conflict among coalitions

\begin{tabular}{llc}
\hline Conflict & $\begin{array}{l}\text { Cases (average conflict } \\
\text { in brackets) }\end{array}$ & Fuzzy-value \\
\hline Strong conflict, observed maximum value (0.79): & Schengen $(0.79)$ & 1.00 \\
& Foreigners $(0.75)$ & 1.00 \\
& Budget $(0.73)$ & 0.87 \\
& Pension $(0.70)$ & 0.81 \\
& Nuclear $(0.69)$ & 0.71 \\
& Fiscal equal. $(0.68)$ & 0.68 \\
& Persons $(0.66)$ & 0.65 \\
& & 0.58 \\
& Telecom $(0.60)$ & 0.50 \\
& Education $(0.55)$ & 0.41 \\
Low conflict, observed minimum value $(0.47):$ & Infrastructure $(0.48)$ & 0.25 \\
& Savings $(0.47)$ & 0.03 \\
& & 0.00 \\
\hline
\end{tabular}


Table A3: Calibration of collaboration among coalitions

\begin{tabular}{llc}
\hline Collaboration & $\begin{array}{l}\text { Cases (average } \\
\text { collaboration in } \\
\text { brackets) }\end{array}$ & Fuzzy-value \\
\hline Strong collaboration, observed maximum value $(0.27)$ : & 1.00 \\
& Telecom $(0.27)$ & 1.00 \\
& Education $(0.23)$ & 0.85 \\
& Pension $(0.21)$ & 0.78 \\
& Budget $(0.20)$ & 0.74 \\
& Savings $(0.17)$ & 0.63 \\
& Infrastructure $(0.14)$ & 0.52 \\
Crossover point: median collaboration $(0.135):$ & 0.52 \\
& Nuclear $(0.14)$ & 0.50 \\
& Schengen $(0.13)$ & 0.48 \\
& Fiscal equal. $(0.13)$ & 0.48 \\
Very weak collaboration, theoretical minimum value (0.00): & 0.15 \\
& Foreigners $(0.04)$ & 0.04 \\
\hline
\end{tabular}


Table A4. Calibration of power relations between coalitions

\begin{tabular}{llc}
\hline Power relations & $\begin{array}{l}\text { Cases (power per coalition } \\
\text { in brackets) }\end{array}$ & Fuzzy-value \\
\hline Dominant coalition (one coalition with 100\% & power), theoretical maximum value: & 1.00 \\
& Education $(89 / 11)$ & 0.89 \\
Savings $(79 / 21)$ & 0.79 \\
Persons $(77 / 21 / 2)$ & 0.77 \\
Budget $(75 / 16 / 8)$ & 0.75 \\
Foreigners $(74 / 26)$ & 0.74 \\
Schengen $(67 / 33)$ & 0.67 \\
Fiscal equal. $(64 / 36)$ & 0.64 \\
Infrastructure $(58 / 15 / 14 / 12)$ & 0.58 \\
Crossover point (one coalition with 50\% of power): & 0.50 \\
Telecom $(47 / 31 / 22)$ & 0.41 \\
Nuclear $(44 / 28 / 27)$ & 0.32 \\
Pension $(36 / 33 / 31)$ & 0.09 \\
\hline
\end{tabular}


Table A5: Necessary conditions
Policy change

Status quo

\begin{tabular}{lcccc} 
& Consistency & Coverage & Consistency & Coverage \\
\hline Strong conflict & 0.70 & n.r. & 0.83 & n.r. \\
Weak conflict & 0.67 & n.r. & 0.66 & n.r. \\
Strong collaboration & 0.74 & n.r. & 0.82 & n.r. \\
Weak collaboration & 0.63 & n.r. & 0.68 & n.r. \\
Dominant coalitions & 0.87 & n.r. & 0.82 & n.r. \\
Competing coalitions & 0.56 & n.r. & 0.75 & n.r. \\
\hline
\end{tabular}




\section{Case descriptions}

\section{Law on nuclear energy (short name in tables: nuclear)}

The law on nuclear energy regulates the production of nuclear energy in Switzerland. It provides no time limitation for existing nuclear power plants, but it includes the possibility that licenses can be limited. New plants can be built, but the provision of licenses for new power plants and geological repositories is subjected to a facultative referendum. Further, the law provides a 10 year moratorium on the export of nuclear waste for reprocessing.

\section{Pension scheme reform (pension)}

The $11^{\text {th }}$ pension reform aimed at the financial consolidation of the first, mandatory pillar of the Swiss pension system. The project comprised retrenchment measures such as an increase of women's pension age or an adjustment of the widow's and the widower's pension level, but also an expansion measure, namely a "social" model of flexibilization of the retirement age.

\section{New fiscal equalization scheme (fiscal equal.)}

The fiscal equalization reform is one of the most far-reaching reforms in Switzerland's recent history. Its goal was fourfold: To build up a more efficient system of fiscal equalization, one that would reduce cantonal differences regarding financial capacity and increase their financial independence; to stop the process of centralization of competences from the cantons to the central state; to disentangle and clarify the competence allocation and financial flows between the Confederation and the cantons; and to foster collaboration among cantons.

\section{Program of budget relief 2003 (budget)}

The program of budget relief 2003 is an exemplary case of the retrenchment and fiscal consolidation measures adopted in the early 2000s. It projected saving measures mainly in the fields of social welfare, traffic, national defense, agriculture, education and research and foreign relations. The saving measures affected most of the federal offices.

\section{Bilateral agreement on the free movement of persons (persons)}

The negotiation on the free movement of persons was an extension to the ten new EU member states of the agreement signed on the same topic during the first bilateral talks. As was already the case with the "old" member states, workers from the ten new EU member states should be allowed to come to Switzerland, and vice versa. Additionally, the related flanking measures to protect Swiss workers against social and wage dumping were strengthened, e.g. by introducing controls by work inspectors.

\section{Bilateral agreement on Schengen/Dublin (Schengen)}

The agreement on Schengen/Dublin consists of two parts. On the one hand, the Schengen system abolishes systematic border control but reinforces cross-border collaboration and exchange of information between member countries. Switzerland also participates in the Schengen visa system. On the other hand, the Dublin convention aims at a better coordination of asylum demands within the EU. This means that asylum seekers are not allowed to apply for asylum in two member states, and the country of the first application is responsible for the asylum seeker. 


\section{Bilateral agreement on the taxation of savings (savings)}

As an alternative to the automatic exchange of information on the savings of EU citizens, which would jeopardize its banking secrecy, Switzerland aligned to the EU model of withholding tax on the interest income from savings of EU citizens residing in Switzerland. Through the agreement on the taxation of savings income, Switzerland supports the EU system of taxing cross-border payments of interest on savings to natural persons.

\section{New law on foreigners (foreigners)}

The new law on foreigners aimed at regulating immigration from non-EU countries, i.e. immigration not regulated by the free movement of persons. It limits immigration from nonEU countries to specialists, managers, and people specifically qualified for a given job. Further, the need for measures of integration is specifically mentioned in the law, but it was also tightened with respect to residence permits, family reunification and punishments for working on the black market or engaging in a fictitious marriage.

\section{New constitutional articles on education (education)}

The new constitutional articles on education represent a step towards the centralization of competences in the domain of education and a strengthening of the Confederation's position in education policy. The new articles require the Confederation and the cantons to collaborate and to coordinate their policies, and to improve the quality and permeability of the Swiss education system. Further, they reinforce the steering capacities of the Confederation, especially in higher education.

\section{Law on telecommunication (telecom)}

The law, inspired by the legal framework of the EU, provides measures to liberalize the telecommunications market in Switzerland. Most importantly, the law provided the unbundling of the last mile and aimed at forcing the incumbent monopolist Swisscom to share access to the last mile with its competitors. However, the liberalization is not perfect, as parts of the access are temporarily limited, and the regulatory commission can step in only based on a suit from competitors.

\section{Law the on infrastructure funds (infrastructure)}

The law on the infrastructure funds established a funds for infrastructure projects. It regulates the financing of the Confederation for road and public transport projects. It provides a legal framework for the funding of projects in the agglomerations, as well as for main roads in the mountainous regions of Switzerland. 